\title{
CORRECTION
}

\section{Correction to: Curative radiation therapy for very elderly bladder cancer patients with localized disease}

\author{
M. Bonet ${ }^{1} @ \cdot$ T. Bonfill ${ }^{2} \cdot$ M. Nuñez ${ }^{3} \cdot$ L. De Verdonces ${ }^{4} \cdot$ E. Mur $^{3} \cdot$ E. Gallardo $^{2}$.

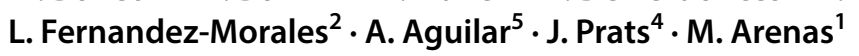

Published online: 15 March 2018

(C) Federación de Sociedades Españolas de Oncología (FESEO) 2018

\section{Correction to: Clin TransI Oncol \\ https://doi.org/10.1007/s12094-017-1804-1}

In the original version of this article the figure captions of Figs. 1 and 2 were interchanged.

The correct captions of Figs. 1 and 2 are listed below.

The original article has been corrected.

The original article can be found online at https://doi.org/10.1007/ s12094-017-1804-1.

\section{Bonet}

bonet.marta@gmail.com

1 Department of Radiation Oncology, Hospital Universitari Sant Joan de Reus, Av. del Dr. Josep Laporte, 2, 43204 Reus, Tarragona, Spain

2 Department of Medical Oncology, Hospital Universitari Parc Taulí, Sabadell, Spain

3 Department of Radiation Oncology, Consorci Sanitari de Terrassa, Terrassa, Spain

4 Department of Urology, Hospital Universitari Parc Taulí, Sabadell, Spain

5 Department of Urology, Consorci Sanitari de Terrassa, Terrassa, Spain

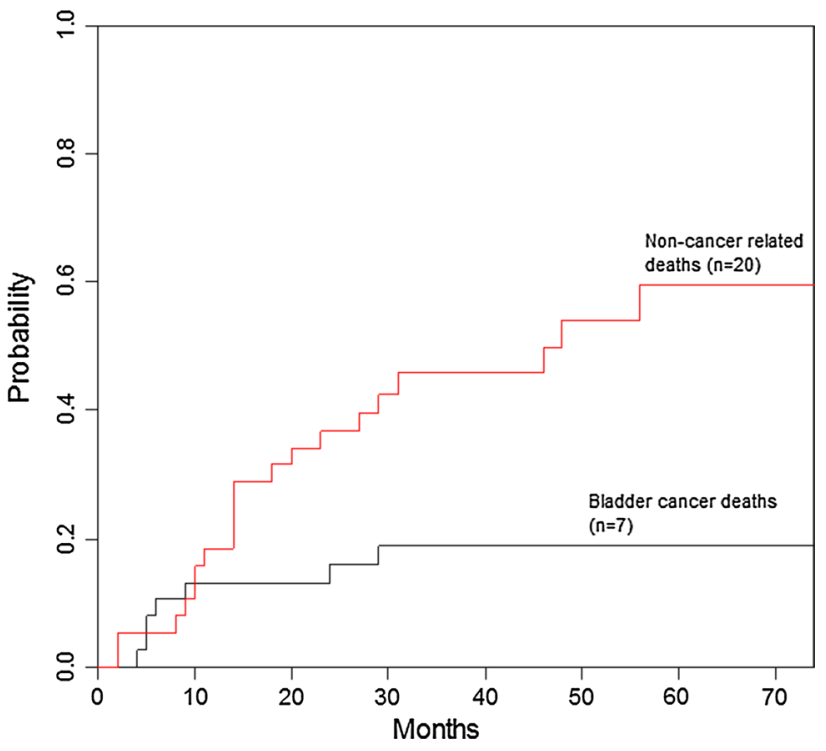

Fig. 1 Cumulative incidence curves for death

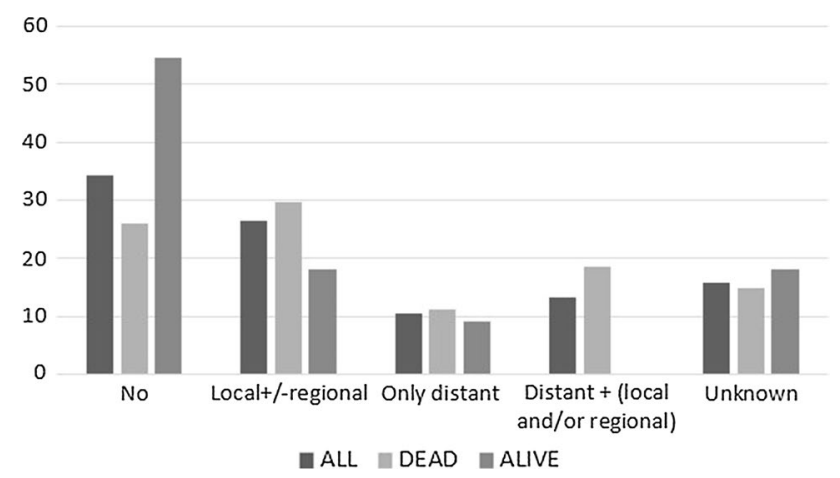

Fig. 2 Main patterns of tumour progression of the cohort 